\title{
Coronavirus (Covid19) and Consuming Behavior Based on Psychological Criteria and Quality of Life Perceptions-A Quantitative Research
}

\author{
Lecturer \\ Department of Business Administration \\ University of Patras \\ Patra, Greece \\ Email: cgeorgi@upatras.gr \\ Greece \\ Despina A. Karayanni \\ Associate Professor of Marketing \\ Department of Business Administration \\ University of Patras \\ Email:karayani@upatras.gr \\ Greece
}

Christina C. Georgi (Corresponding Author)

\section{ABSTRACT}

The spread of the Covid-19 pandemic changed significantly our everyday life. Many established habits have altered and people were imposed to live more distant than before. These brought notable shifts in the way we feel, behave, and consequently in our purchasing ways. This paper aims to investigate whether perceived differences in quality of life, stress, and depression led to different ways of adapting to new imposed behavioral patterns. Furthermore, we tried to identify if these perceptions affected our purchasing ways, during the quarantine period.

\section{Keywords: Covid-19, quality of life, stress, depression, consumers' segments}

\section{Introduction}

In December 2019, pneumonia of unknown origin was identified in a patient in the Yuhan region of China (Lei et al. 2020). The pathogen was recognized as a new betacoronavirus RNA, called severe acute respiratory syndrome coronavirus 2 or SARS-CoV-2 for short, as it has a phylogenetic similarity to the SARS-CoV virus (Guan et al. 2020). WHO declared on 11th of March 2020, the outbreak as a global pandemic (Anand et al. 2020), and, according to WHO's reports, until October 28, 20, 43.540 .739 cases of Covid-19 infections have been confirmed as well as 1.160 .650 deaths worldwide (WHO 2020d). The evolving situation altered drastically people's lives around the World. Many countries have taken severe measures to stem the spread of the virus, which concluded in civilians' social activities restrictions both locally and internationally, resulting in declining trends in supply and demand, and altering all aspects of everyday, economic and social life (Nicola et al. 2020). So it can be expected that the Covid-19 pandemic would have a disturbing impact on health, emotional and social functioning.

In Greece, particularly, the government-imposed lockdown on 23th of March with extreme restrictions on social contact, ability to work, stipulated working from home in many cases, and significantly reduced access to public services. For Greek people, the unprecedented efforts of the government to establish the practice of physical distancing, which is called social distancing, resulted in changes in behavioral norms, and lockdowns to most of the daily functions. Taking into account that in Greece since the start of the economic crisis there was a skyrocketing increase in mental illnesses, with over 550,000 Greeks suffering from depression (Kiloudis et al. 2015), and a 120\% rise in drug and alcohol misuse, and demand for mental health services (Madianos 2013, Kentikelenis et al. 2014), we can comprehend that the emergence of the pandemic and the measures taken to prevent it will have significant consequences in the society.

Due to the relatively short time that this pandemic has invaded our lives, there is limited time research of the subject matter in contemporary marketing literature. Moreover, marketing literature seems to have fallen behind on how specific psychological variables, such as perceptions on quality of life, stress, and depression may characterize civilian's behavior to comply with the proposed governmental measures, especially in terms of purchasing behavior regarding Coronavirus protecting material.

This research attempts to add some pieces of evidence on the subject matter. Specifically, we want to examine if the perceived quality of life, stress, and depression, having in mind the measures taken to prevent Covid-19 spreading, has led to differences in behavior and purchasing. To do that, we segmented consumers, based on the quality of life and perceived stress and depression, and examined if there were any differences regarding behavioral adjustment and purchasing practices. This would enable us to better understand consumers' perceptions of how they operate in various circumstances. Furthermore, it might guide policymakers in 


\section{(C) Center for Promoting Education and Research (CPER) USA}

wwW.cpernet.org

adapting communication messages to respective target audiences, improving behavioral adjustment and limiting stress and depression, and improving quality of life.

To these ends, we performed qualitative exploratory research that was performed from March to May of 2019, based on a research sample of 1807 respondents, using the electronic data collection method.

This paper is organized as follows. First, we provide a theoretical background on the measures of the subject matter.

Next, we performed a series of descriptive and advanced statistical analyses, on our research data, to examine if we might segment the research sample into meaningful consumer clusters, based on their perceptions regarding their quality of life, along with perceived stress and depression measures. Following, we examined the relationships of the performed clusters with the behavioral adjustment and purchases and we discuss the research findings and implications to public policymakers. The paper ends by providing the research limitations, together with directions for future research.

The role of Covid19 pandemic upon consumers' quality of life, stress, and depression Since Covid-19 is a life threatening condition, it is bound to affect the quality of life in total, even if it is acknowledged that health, functional ability, and clinical status are compiled to only one dimension of quality of life [1]. Human needs, expectations, subjective wellbeing, a cognitive judgment of satisfaction with one's life in the context of culture and value systems in which one lives about one's goals standards, and concerns per se, form quality of life [2,3]. The first indications of the pandemic impact, worldwide, indicate serious effects on employment, income, means of subsistence, and personal depth [4]. So the outcome of this crisis seems to affect the quality of life in total, and this comes in coherence with the fact that different degrees of severity of the outbreak, economic status, medical services, and circulation of Covid19 information, result in differences in the prevalence of symptoms of adverse psychiatric outcomes, fear, and turbulence [5]. The first searches that were conducted in early 2020, in China, showed the only mild stressful impact of the pandemic on mental health and quality of life [6]. But with time raises in anxiety and depression and some aspects of discomfort were spotted [7] and lower scores in some physical and psychological domains of the quality of life were noted [8]. In the same direction, moderate or high levels of perceived stress were reported, and stress was found to have a strongly negative association with quality of life during the pandemic in another study [9].

Any disaster of large scale is accompanied by increases depression and stress disorders [10], let alone a pandemic, which has caused deep-rooted, existential anxiety, experienced as a threat to peoples' common identity, and the sense of their place in the world [11]. In the same vein, a study in the UK showed an overall increase in the mental distress in the population compared with the year before the Covid-19 pandemic [12]. In the USA the adaptation to confinement and distancing has driven confusion and uncertainty [13], especially those with a pre-existing or suspected mental health diagnosis reported significantly higher rates of distress symptoms [14].

\section{Behavioral adjustment in Covid-19 era}

It has been well established from the $70 \mathrm{~s}$, that the major task of preventive medicine has become patterns of behavior that may decrease the risk of diseases in the population [15]. Through the year's foundations, insurance companies, medical associations, and health ministries have recognized the prevention stake in health provision and attempted to modify maladaptive habits and practices [16] Today with the outbreak of Covid-19 some aspects of social behavior are increasingly being interpreted as a protective factor. Staying at home, avoiding crowded places, washing hands regularly, use of car instead of public transport are some of the prevented measures that are recommended [17]. But why would and should someone adjust one's behavior to the suggested rules, if it was not the threat of getting sick and the probability of dying. When people anticipate the most critical risk, death, negative emotions overflow, and simultaneously an internal mechanism to restrain them is activated [18-21]. Selfpreservation is an instinct from which all human motives are ultimately derived [22], and this drives people to follow the worldview of their culture to feel safer or to abandon other views [23]. Since the dominant perspective in compliance with the measures taken, we can assume that people will comply and act accordingly. But as it has been proven in other lifethreatening cases sometimes self-esteem could alter an individual's reaction and make them lean toward more lifeendangering choices [24]. So, the concept of ourselves plays a very important role in rejecting or embracing certain behaviors. On the other hand, there is a strong relationship between this and depression as well as anxiety [25], and quality of life [26]. Taking these into account, we can hypothesize that different levels of quality of life, depression, and anxiety will lead to different levels of compliance towards the directives for social distancing or personal hygiene.

Dealing with purchases for Covid-19, to wit masks, gloves, drugs, and antiseptics The use of masks, gloves, and antiseptics has become omnipresent since the outbreak of the pandemic with some countries to enforce compulsory face mask policies in public areas, and others to adopt a risk-based approach in offering recommendations for using face masks. UK, Germany, the USA, and WHO did not recommend the use of face masks to healthy individuals except those who take care of ill people, in contrast to China and Hong Kong which proposed a general use of masks as a measure to address the spread [27-31]. The Greek government during the first lockdown impose the use of masks only in close crowed places and health professionals. Although improper use of masks could increase the risk of infections, the use of face masks by 


\section{(C) Center for Promoting Education and Research (CPER) USA}

wwW.cpernet.org

the public has surpassed the global supply during the Covid-19 pandemic [32]. The production of antiseptics, which protect indirectly ruling out transmission through hand contact or by contaminated inanimate surfaces, inactivating the virus, in many cases has been insufficient as well and could not cover the demand [33].

The use of drugs to restore health is an indisputable practice, but many times this deviates and leads to polypharmacy, a well-established habit in Greece [34, 35]. But this trend apparent with self-medication tendency, since the start of the pandemic has been reported to have increased worldwide [36]. According to research that took place in Peru there were significant percentages of self-medication, even with drugs with insufficient scientific evidence [37].

When people buy something, for whatever reason, they base this decision on the way they will use the product, as well as how well it serves this use. Further, the task this product serves, about other products and their usage behavior, forms the overall consumption system [38]. It is common sense that well-being comes from the attainment of wealth and the purchase and acquisition of goods and services [39]. It is also assumed that the quality of life is the level of satisfaction as a result of the consumption of market goods [40, 41].

In every socio-cultural environment, widely shared beliefs usually represent what is desirable. These beliefs are implanted into individuals through socialization and education, nevertheless through the internet or television information spreads, with some modifications as personality and attitude moderate the assimilation [42]. Needs reflect an individual's personality and consumption in a way that refers to subjective beliefs about desirable ways to attain personal needs.

Customers, in general, are more interested in benefits they get from buying, using, or consuming the product than its technical features [43] and they consume something apart from its functional use for social, affective, hedonic, and situational benefits. This means that except for its physical performance a product would be bought to be in accordance to social tendency, arousing feelings or affective states, the satisfaction of needs of pleasure or distraction from work or anxiety, and meeting situational needs in specific circumstances. Furthermore, the influence arising from factors particular to a specific time and place, aka situational influence, is independent of a consumer's characteristics [44]. But the importance of product benefits varies among people due to their characteristics [45]. Also, mental and behavioral outcomes are interrelated sets, where mental should have a direct impact on behavioral outcomes [46].

In the time of emergencies, such as a pandemic, the consumption behavior is changing to more impulsive modes, consciously or unconsciously, and often results in sudden, spontaneous, of quick-judgment, and unplanned consumption [47]. In such cases, the external environment leads consumers to make rush decisions without reasoning [48]. In agreement with that studies have found that individuals seek immediate enjoy, under these circumstances, and consuming is a way of over-indulge $[49,50]$. Also, impulsive consumption can result in the acquirement of immediate satisfaction and mood upturn. [51]. When people have to deal with uncertain situations, as the Covid-19 outbreak and the accompanying changes it brought to everyday life, they feel that they lost their perceived control of life, becoming less healthy and less happy [52, 53], while anxiety and other negative psychological outcomes bloom [54]. To compensate for this loss and the negative feelings of anxiety, as well as to regain a sense of control, they impulsively make purchasing decisions to obtain external resources $[55,56]$. As shown in research conducted in China during the Covid-19 pandemic, a reduction in peoples' perceived control was followed by an increase in their impulsive consumption and a materialist tendency has been noticed [57]. But another study in the USA mentioned that across all spending categories a reduction in movement is related to a reduction in spending, with the least reduction to be observed for credit card spending [58]. So, to rule out the possibility of having a bias in our findings of consumer behavior due to restriction measures we will limit our research field towards rather inexpensive goods associated with the pandemic, like masks and gloves and antiseptics, and, of course, medicines. So, we can hypothesize that different levels of quality of life, depression, and anxiety will lead to different levels of consumption.

The present study wants to investigate relationships between quality of life, stress, depression, and purchasing behavior, as well as, adaptation to behavioral patterns during the quarantine period for Covid-19. We hypothesize that psychological variables, as well as the quality of life, may explain observed differences in the way consumers behave.

\section{Materials and methods}

The constructed research instrument was developed based on extensive scientific literature research. First, we delved into the literature about the Covid-19 pandemic, the recent literature about the precautionary measures that should be adopted by the general population, to stop the spreading of Covid-19 in the community, consumer behavior, social behavior, quality of life, consumption, social psychiatry, and mental health.

\section{Sampling}

We used subjective sampling, following the guidance of marketing research literature [59] and the electronic data collection method [60]. A link was placed on the Internet inviting people to answer and participate in the survey, and was activated in March 2020, just after the institution of the quarantine measures by the Greek government, and was up and running, until the end of May 2020.

\section{Measures}

We retrieved measures from the WHOQOL-BREF [61] and the hospital anxiety and depression scale (HADS) 


\section{(C) Center for Promoting Education and Research (CPER) USA}

wwW.cpernet.org

[62] to measure the quality of life, stress, and depression, respectively. We further downsized the number of measures to be more approachable for the participant, hence we covered the four domains physical health, psychological health, social relationships, and the environment. At the same time, we performed quality research with 10 key informants from the health sector, mainly physicians. The participants expressed their attitudes through open-ending questions. The aspects that were most frequently mentioned were further examined for empirical evidence or theoretical support. Based on the above preliminary research we constructed the quantitative measure instrument of our study. The measures comprised eight batches of items, namely overall quality of life, activities of daily living, personal relationships, safety and security, financial resources, healthcare, depression, and anxiety. To measure the behavior of the public, during the quarantine, and how they adapted to the emerging conditions, we used three constructs, behavioral adjustment, purchase of protective means, and purchase of drugs, based on the recommendations by WHO [63], that addressed personal protective measures and the tendency to polypharmacy which exists in the Greek society [64]. The questionnaires also included demographic, sex, age, family status, and socioeconomic data, in terms of education, family income, and employment measures.

\section{Measures Reliability and Validity}

Specifically, we performed factor analysis using the Maximum Likelihood method and Promax rotation, to maximize the differences between factors and to assess unique relationships between each factor and the variables [65]. The first-factor analysis procedure resulted in six factors, that refer to the quality of life and the second into two, depression and anxiety, as expected. The third provided us with four factors, drug purchase, protective means purchase, public avoidance, and personal hygiene, concerning the behavioral adjustment. All of the above factors had eigenvalues greater than one and explained $73,84 \%, 67,89 \%$, and $68,207 \%$ of the total variance of the three-factor analyses respectively. Sequentially we subjected the construct items to a series of reliability analyses which produced acceptable levels of Cronbach alpha statistics, ranging from .610 to .915 thus enabling us to sustain that all twelve constructs were reliable $[66,67]$.

\section{Demographic Characteristics}

The response sample comprised 1950 respondents, of which 1807 fully completed the respective questionnaire, thus, finally included in the analysis. The average age of the participants was 25 years, whilst, $82 \%$ of our sample belonged to the age class younger than 45 years. Men and women represented 42,2\% and 57,8\% respectively, in our research sample. Regarding family status, only $27,8 \%$ were married and another $24,4 \%$ cited having children. As far as the level of education is concerned, this was quite high, as $62,8 \%$ of our participants had a university degree and another $11,3 \%$ cited to have a postgraduate degree.

\section{Results}

First, we subjected our main research items to a series of T-test means comparisons, using time of response as the grouping variable, which produced no meaningful results, thus indicating that our sample was homogenous. Next, we proceeded to a series of reliability scale analyses, producing Cronbach Alphas >.60, thus indicating that our measures were reliable.

As a next step, to tap our research purposes, we performed advanced statistics, including, correlation analysis, cluster analysis, and ANOVAs.

The relationships among the research constructs are depicted in the correlation analysis of Table 1

Table 1. Corellations, Number of items in scale, Mean, Standard Deviation and Coefficient Alpha of the main constructs.

\begin{tabular}{|c|c|c|c|c|c|c|c|c|c|c|c|c|c|}
\hline \multicolumn{14}{|c|}{ Summary statistics and construct correlations } \\
\hline \multicolumn{14}{|c|}{ Intercorrelations } \\
\hline & Variables & 1 & 2 & 3 & 4 & 5 & 6 & 7 & 8 & 9 & 10 & 11 & 12 \\
\hline 1 & overall quality of life & - & & & & & & & & & & & \\
\hline 2 & activities of daily living & 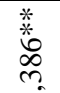 & - & & & & & & & & & & \\
\hline 3 & personal relationships & $\begin{array}{l}\text { 晜 } \\
\text { 字 }\end{array}$ & $\begin{array}{l}\text { * } \\
\text { *ैं } \\
\text { ㄱ. }\end{array}$ & - & & & & & & & & & \\
\hline 4 & safety and security & 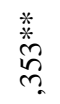 & 蓄 & 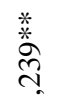 & - & & & & & & & & \\
\hline 5 & financial resources & $\begin{array}{l}\text { 粗 } \\
\text { 。 }\end{array}$ & 菜 & $\frac{*}{\stackrel{*}{*}}$ & $\stackrel{\text { 卷 }}{\stackrel{0}{m}}$ & - & & & & & & & \\
\hline
\end{tabular}




\begin{tabular}{|c|c|c|c|c|c|c|c|c|c|c|c|c|c|}
\hline 6 & Healthcare & 菜 & $\begin{array}{l}\text { 粰 } \\
\stackrel{9}{\sigma}\end{array}$ & $\begin{array}{l}\text { 晜 } \\
\text { ले }\end{array}$ & $\begin{array}{l}\text { 菜 } \\
\text { ते }\end{array}$ & 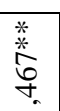 & - & & & & & & \\
\hline 7 & Depression & $\begin{array}{l}\frac{*}{*} \\
\stackrel{m}{*} \\
\end{array}$ & $\begin{array}{l}\text { * } \\
\stackrel{*}{*} \\
\stackrel{0}{*}\end{array}$ & 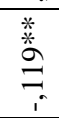 & 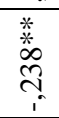 & $\begin{array}{l}\stackrel{*}{*} \\
\stackrel{*}{*} \\
\stackrel{7}{i}\end{array}$ & 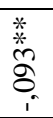 & - & & & & & \\
\hline 8 & Stress & $\begin{array}{l}\stackrel{*}{*} \\
\stackrel{*}{*} \\
\end{array}$ & $\begin{array}{l}\text { * } \\
\stackrel{*}{\sigma} \\
\stackrel{2}{*}\end{array}$ & $\begin{array}{l}\frac{*}{*} \\
\stackrel{*}{n} \\
\stackrel{2}{r}\end{array}$ & $\begin{array}{l}\frac{*}{*} \\
\stackrel{*}{n} \\
?\end{array}$ & 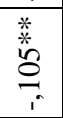 & \begin{tabular}{l}
$*$ \\
\multirow{2}{*}{} \\
0 \\
0
\end{tabular} & 蒂 & - & & & & \\
\hline 9 & $\begin{array}{l}\text { purchase of protective } \\
\text { means }\end{array}$ & $\overline{0}$ & $\delta_{i}$ & ñ & 养 & $\tilde{\sigma}$ & 䔄 & $\stackrel{\text { 尊 }}{m}$ & 卷 & - & & & \\
\hline 10 & drug purchase & $\vec{\delta}$ & $\begin{array}{l}\text { * } \\
\text { 。 } \\
\text { ؛ } \\
\text { i }\end{array}$ & $\begin{array}{l}\text { 莫 } \\
\stackrel{+}{5} \\
\text { i }\end{array}$ & 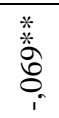 & \%ै. & 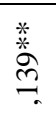 & $\begin{array}{l}\text { * } \\
\text { ते } \\
\text { ते }\end{array}$ & \begin{tabular}{l}
$\stackrel{*}{*}$ \\
$\stackrel{*}{\infty}$ \\
\hdashline
\end{tabular} & 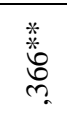 & - & & \\
\hline 11 & personal hygiene & 8 & है. & $\overline{0}$ & $\tilde{o}_{i}^{n}$ & $\begin{array}{l}* \\
* \\
* \\
0 \\
0\end{array}$ & 容 & 萻 & 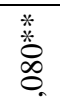 & 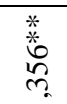 & 晜 & - & \\
\hline \multirow[t]{5}{*}{12} & public avoidance & 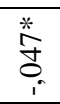 & $\begin{array}{l}* \\
0 \\
\infty \\
0 \\
i\end{array}$ & 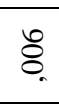 & ஜ: & $\overrightarrow{\theta_{i}}$ & $\stackrel{0}{0}$ & 蒡 & 蒡 & 萧 & 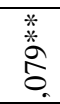 & $\stackrel{*}{\stackrel{*}{*}}$ & - \\
\hline & Number of items in scale & 4 & 3 & 2 & 3 & 3 & 6 & 5 & 2 & 3 & 3 & 2 & 2 \\
\hline & Mean & 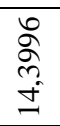 & $\begin{array}{l}\text { N } \\
\widehat{0} \\
\stackrel{0}{0} \\
0\end{array}$ & $\begin{array}{l}\text { P } \\
\text { nn } \\
\sim\end{array}$ & $\begin{array}{l}\text { రి } \\
0 \\
0 \\
0\end{array}$ & $\begin{array}{l}0 \\
\stackrel{0}{0} \\
\dot{q} \\
a\end{array}$ & $\begin{array}{l}+ \\
\infty \\
\cong \\
\infty \\
\infty\end{array}$ & $\begin{array}{l}\stackrel{P}{a} \\
a \\
\dot{U}\end{array}$ & $\begin{array}{l}r \\
\infty \\
0 \\
0 \\
n\end{array}$ & $\begin{array}{l}\vec{\sigma} \\
\stackrel{=}{=}\end{array}$ & 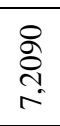 & $\begin{array}{l}\tilde{N} \\
\hat{n} \\
\infty \\
\infty\end{array}$ & $\begin{array}{c}\infty \\
\infty \\
\infty \\
\infty\end{array}$ \\
\hline & Standard Deviation & 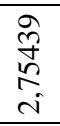 & $\begin{array}{l}\hat{n} \\
\hat{\Omega} \\
i\end{array}$ & $\begin{array}{l}\overrightarrow{5} \\
\text { o. } \\
\stackrel{n}{n}\end{array}$ & $\begin{array}{l}\frac{2}{2} \\
\hat{b} \\
\text { in }\end{array}$ & 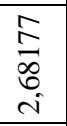 & 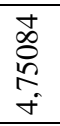 & $\begin{array}{l}0 \\
\infty \\
\infty \\
\infty \\
\infty \\
\infty\end{array}$ & $\begin{array}{l}\infty \\
\circ \\
\stackrel{\sigma}{2} \\
\end{array}$ & 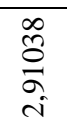 & 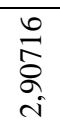 & $\underset{\sim}{\stackrel{\mathcal{G}}{J}}$ & 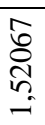 \\
\hline & Coefficient Alpha & $\begin{array}{l}\infty \\
\infty \\
\infty\end{array}$ & $\stackrel{2}{?}$ & $\begin{array}{l}0 \\
b \\
0\end{array}$ & $\ddot{\infty}$ & $\begin{array}{l}\mathscr{D} \\
\infty \\
\infty\end{array}$ & \& & న్ & $\frac{n}{a}$ & ¿. & ㅇ․ & $\frac{0}{6}$ & $\underset{\infty}{\infty}$ \\
\hline
\end{tabular}

Sequentially, we applied cluster analysis, grouping the research constructs. The mean cluster center values for the three clusters participants based on their responses, regarding the produced are presented in Table 2, together with the ANOVAs of the eight factors. Specifically, K-means (non-hierarchical) cluster cluster means and significance levels, which provided support analysis was performed, as it is a commonly used clustering for the discriminant validity of the cluster solution. Based on technique [68, 69]. The cluster analysis resulted in an their distinctive measures, the produced three clusters were interpretable solution, producing three clusters, all of which named Balanced, Stressed, and Depressed, respectively. could be defined uniquely and meaningfully, based on all eight

Table 2. Cluster centre's, cluster membership and ANOVA statistics

\begin{tabular}{|l|c|c|c|c|c|}
\hline \multicolumn{5}{|c|}{ Final Cluster Centers, Cluster Membership \& ANOVA Statistics } \\
\cline { 2 - 7 } & \multicolumn{3}{|c|}{ Clusters } & \multicolumn{2}{c|}{ Sig. } \\
\cline { 2 - 7 } & Balanced & Stressed & Depressed & \multicolumn{2}{c|}{ F } \\
\hline No of cases in each cluster & 509 & 700 & 598 & &, 000 \\
\hline Overall quality of life & 14,61 & 15,65 & 12,76 & 223,344 &, 000 \\
\hline Healthcare & 16,83 & 22,46 & 14,17 & 1211,344 &, 000 \\
\hline Financial resources & 9,62 & 10,81 & 7,70 & 286,928 &, 000 \\
\hline Safety and security & 11,40 & 11,67 & 9,76 & 164,336 &, 000 \\
\hline Activities of daily life & 10,94 & 11,22 & 9,78 & 83,301 &, 000 \\
\hline Personal relationships & 7,73 & 7,84 & 7,01 & 51,738 &, 000 \\
\hline Depression & 11,21 & 15,37 & 17,54 & 631,491 &, 000 \\
\hline Stress & 4,14 & 5,06 & 5,84 & 117,454 & \\
\hline
\end{tabular}


Each cluster had a distinct profile of characteristics which comprise the quality of life, stress, and depression. Thus, the first cluster named the Balanced, comprised people that scored highest on life quality and lowest on depression and anxiety $(\mathrm{n}=509,28,17 \%)$. The second cluster, the Stressed $(n=700,38,74 \%)$, indicated a lesser score, then, the third group (the Depressed), about depression, though a higher stress score, than, the first cluster (the Balanced). Finally, the third cluster $(\mathrm{n}=598,33,09 \%)$ scored highest in depression and lowest in the life quality variables, thus, justifying its name as Depressed.

Specifically, the Stressed scored highest of all three, in every parameter concerning the quality of life, namely overall life quality, healthcare, financial resources, safety and security, activities of daily life, and personal relationships, and at the same time, they scored quite high in stress and depression, which did not coincide with previous empirical research [70]. But this finding may be due to the Covid-19 pandemic's repercussions, along with the measures that had been taken by the government, which erased public anxiety and depression. It can be argued that mobility caused by Covid-19 threatened to harm their standard of living. Furthermore, the quarantine status altered citizens' way of living, restricting them from their usual activities in everyday life, which also may justify the research findings of increased depression and stress [7173]. The last cluster, the Balanced, scored quite high in the parameters of life quality, leaning towards the Stressed, and at the same time, they scored rather low in depression and anxiety. This finding is consistent with the fact that the perceived situation of quarantine and pandemic crisis may not be interpreted in the same way by the population, as a whole, even though some behaviors might look the same $[74,75]$. The Depressed scored lowest of all three, in life quality and high in depression and anxiety, which might be anticipated since the lower quality of life is associated with higher rates of stress and depression [76, 77].

As a next step, to test the relationships among the three types of consumers and behavioral adjustment and purchasing habits, we proceeded to a series of ANOVAs, among the three groups and the two consumer behavioral variables, which accounted for drugs purchases, protective means purchases, along with enhancing personal hygiene and avoiding social contacts variables, as stated by WHO and other health organizations.

The assumptions of the One-way ANOVA were valid, so we proceeded to the application of the method, and the results showed that at least one category is significantly different than the others (Table 3).

Table 3. One-way ANOVA.

\begin{tabular}{|c|c|c|c|c|c|}
\hline & \multicolumn{5}{|c|}{ ANOVA } \\
\hline & $\begin{array}{l}\text { Sum of } \\
\text { Squares }\end{array}$ & df & Mean Square & $\mathrm{F}$ & Sig. \\
\hline \multirow{3}{*}{$\begin{array}{l}\text { Purchase of protective } \\
\text { means }\end{array}$} & 1056,107 & 2 & 528,054 & 66,891 & ,000 \\
\hline & 14241,254 & 1804 & 7,894 & & \\
\hline & 15297,361 & 1806 & & & \\
\hline \multirow{3}{*}{ Drug purchase } & 474,137 & 2 & 237,068 & 28,919 & ,000 \\
\hline & 14764,078 & 1801 & 8,198 & & \\
\hline & 15238,215 & 1803 & & & \\
\hline \multirow{3}{*}{ Public avoidance } & 116,701 & 2 & 58,351 & 25,930 & ,000 \\
\hline & 4059,586 & 1804 & 2,250 & & \\
\hline & 4176,288 & 1806 & & & \\
\hline \multirow{3}{*}{ Personal hygiene } & 121,806 & 2 & 60,903 & 24,053 & ,000 \\
\hline & 4567,804 & 1804 & 2,532 & & \\
\hline & 4689,609 & 1806 & & & \\
\hline
\end{tabular}

To detect the statistical significance of differences each variable. For each pair of clusters, we observed the mean between categories, Tuckey's post-hoc tests were performed. difference and its standard error, and the p-value. Table 4 displays the comparisons for each pair of clusters and 


\section{(C) Center for Promoting Education and Research (CPER) USA}

Table 4. Tuckey's post-hoc tests

\begin{tabular}{|c|c|c|c|c|c|}
\hline Dependent Variable & (I) Cluster name & (J) Cluster name & Mean Difference (I-J) & Std. Error & $\mathrm{p}$-value \\
\hline \multirow{6}{*}{$\begin{array}{l}\text { Purchase of protective } \\
\text { means }\end{array}$} & \multirow{2}{*}{$\begin{array}{c}\text { Balanced } \\
(\text { Mean=10,4990) }\end{array}$} & Stressed & $-1,75955^{*}$ & , 16367 &, 000 \\
\hline & & Depressed & $-1,61804 *$ & ,16944 &, 000 \\
\hline & \multirow{2}{*}{$\begin{array}{c}\text { Stressed } \\
(\text { Mean=12,2586) }\end{array}$} & Balanced & $1,75955^{*}$ &, 16367 & 000 \\
\hline & & Depressed &, 14151 & , 15646 & ,638 \\
\hline & \multirow{2}{*}{$\begin{array}{c}\text { Depressed } \\
(\mathrm{Mean}=12,1171)\end{array}$} & Balanced lives & $1,61804 *$ & , 16944 & 000 \\
\hline & & Stressed &,- 14151 &, 15646 & ,638 \\
\hline \multirow{6}{*}{ Drug purchase } & \multirow{2}{*}{$\begin{array}{c}\text { Balanced } \\
(\text { Mean=6,4126) }\end{array}$} & Stressed & $-1,23600 *$ & , 16678 & 000 \\
\hline & & Depressed &,$- 96054 *$ & , 17287 & 000 \\
\hline & \multirow{2}{*}{$\begin{array}{c}\text { Stressed } \\
(\text { Mean=7,6486) }\end{array}$} & Balanced & $1,23600 *$ & , 16678 &, 000 \\
\hline & & Stressed &, 27546 & , 15965 &, 196 \\
\hline & \multirow{2}{*}{$\begin{array}{c}\text { Depressed } \\
(\text { Mean=7,3731) }\end{array}$} & Balanced & ,96054* & , 17287 & 000 \\
\hline & & Stressed &,- 27546 & , 15965 & ,196 \\
\hline \multirow{6}{*}{ Public avoidance } & \multirow{2}{*}{$\begin{array}{c}\text { Balanced } \\
\text { (Mean=8,2358) }\end{array}$} & Stressed &,$- 44139 *$ & 08738 & 000 \\
\hline & & Depressed &,$- 64050 *$ & ,09047 &, 000 \\
\hline & \multirow{2}{*}{$\begin{array}{c}\text { Stressed } \\
(\text { Mean=8,6771) }\end{array}$} & Balanced & ,44139* & ,08738 &, 000 \\
\hline & & Depressed &,$- 19911^{*}$ & 08353 & 045 \\
\hline & \multirow{2}{*}{$\begin{array}{c}\text { Depressed } \\
(\text { Mean=8,8763) }\end{array}$} & Balanced &, $64050 *$ & ,09047 &, 000 \\
\hline & & Stressed &, $19911 *$ & 08353 & 045 \\
\hline \multirow{6}{*}{ Personal hygiene } & \multirow{2}{*}{$\begin{array}{c}\text { Balanced } \\
(\text { Mean=7,9607) }\end{array}$} & Stressed &,$- 57072 *$ & 09269 & ,000 \\
\hline & & Depressed &,$- 58444 *$ & ,09596 & ,000 \\
\hline & \multirow{2}{*}{$\begin{array}{c}\text { Stressed } \\
(\text { Mean=8,51314) }\end{array}$} & Balanced 1 &, $57072 *$ & ,09269 & ,000 \\
\hline & & Depressed &,- 01372 & ,08861 & ,987 \\
\hline & \multirow{2}{*}{$\begin{array}{c}\text { Depressed } \\
(\text { Mean=8,5452) }\end{array}$} & Balanced &, $58444 *$ & ,09596 & ,000 \\
\hline & & Stressed & ,01372 & ,08861 & ,987 \\
\hline
\end{tabular}

As depicted in Table 4, the three clusters, namely, the Balanced and Stressed and Depressed, differ in purchases of protective means. At the same time, there is no significant difference between the Stressed and the Depressed in regard to the quality of life measures, the medicines' purchases, and personal hygiene measures. But concerning public avoidance, each group holds a different attitude, which is significantly different from all others. We can observe that the most social distant are the Depressed, followed by Stressed and the Balanced, which are the least distant. Therefore, we can conclude that stress and depression play a much stronger role in people's attitudes towards dealing with the Covid-19 pandemic than other aspects of life quality.

\section{Discussion}

The Covid pandemic 19 and all the government's precaution measures that followed, brought great changes in daily life. Almost all aspects of citizens' everyday life were affected, along with mental state and the ways of acting and behaving. Our research findings indicated that respondents may be segmented into three major groups, according to their perceived quality of life, stress, and depression. One with the medium perception of life quality, lesser stress and depression, one with a high perception of life quality, but with more stress and depression, and a third one, characterized by rather low scores on quality of life parameters, though quite high scores on stress and depression. We named these groups as Balanced, Stressed, and Depressed, respectively. The Balanced group showed less need for purchasing, compared to the other two 


\section{(C) Center for Promoting Education and Research (CPER) USA}

www.cpernet.org

counterparts, which is in accordance with the fact that attitude, with the Depressed being the most distant, followed purchasing may be a way of compensating for anxiety and by the Stressed and the Balanced to be less distant of all. It other negative psychological outcomes $[55,56]$. The Stressed appears that the Depressed comply with the government's group was the one to lose the most, as they held the best motto 'staying at home' that implies providing greater safety. quality of life rates before the Covid-19 pandemic, and thus the However, following prior research, such internal restraining aggravated levels of stress and depression may be due to the perceived uncertainty of maintaining the same way of life. Finally, the Depressed counterparts exposed the lowest rates of quality of life measures, and higher rates of stress and depression, at the same time. This finding may be also due to the fact that the changes brought with the advent of the pandemic, might have threatened their way of life, and made them fear that their standard of living would be further reduced. On the other hand, the Balanced seemed to be the least influenced of all three in the stressing and depression measures, which also reflected upon low scores of purchasing variables.

The same attitudes may apply to hygiene measures, with the Balanced to show statistically different attitudes than the Stressed and Depressed clusters. The two groups, Stressed and Depressed, have shown no significant difference between them. The Balanced have accepted the measures which apply to personal hygiene since they scored high, but they seemed to be less attached to them, than the other clusters. This seems to comply with prior research, depicting that the more insecure someone feels, the more will comply with the instructions given, in order to feel safer [23].

Finally, as far as public avoidance is concerned, research findings indicated that every group holds a different mechanisms are expected to raise negative feelings, which justifies that the more a person is depressed the more he/she will seek isolation in order to feel safer [18-21].

\section{Implications, limitations, and future research}

The present study examined the effects of quarantine in the behavior and consuming trends regarding Covid-19 prevention purchases in Greece. The results could provide the policymakers with some useful hints, in order to communicate more effectively their strategy for dealing with the pandemic. For example, they can inform the public and give instructions in a way that does not intensify stress and depression, but sensitizing them, because as it has been shown a small increase in stress leads to better compliance to the instructions, and consequently better address the spread of the pandemic.

In order to generalize our findings and test the validity of our findings across different cultures, we should extend the research sample to other European countries and perhaps in various regions across the world. Moreover, we may repeat the research in the current time quarantine period, for comparison reasons. We may also proceed to qualitative research to a more in-depth examination of the reasons that the Covid-19 pandemic incurs differential effects upon the aforementioned market clusters.

\section{References}

Ferrans, C.E. Quality of life: conceptual issues. in Seminars in oncology nursing. 1990.

Rejeski, W.J. and S.L. Mihalko, Physical activity and quality of life in older adults. The Journals of Gerontology Series A: Biological sciences and medical sciences, 2001. 56(suppl_2): p. 23-35.

Karimi, M. and J. Brazier, Health, health-related quality of life, and quality of life: what is the difference? Pharmacoeconomics, 2016. 34(7): p. 645-649.

Joyce, R. and X. Xu, Sector shutdowns during the coronavirus crisis: which workers are most exposed. Institute for Fiscal Studies Briefing Note BN278, 2020. 6.

Xiong, J., et al., Impact of COVID-19 pandemic on mental health in the general population: A systematic review. Journal of affective disorders, 2020.

Zhang, Y. and Z.F. Ma, Impact of the COVID-19 pandemic on mental health and quality of life among local residents in Liaoning Province, China: A cross-sectional study. International journal of environmental research and public health, 2020. 17(7): p. 2381.

Ping, W., et al., Evaluation of health-related quality of life using EQ-5D in China during the COVID-19 pandemic. PloS one, 2020. 15(6): p. e0234850.

Wang, X., et al., Bidirectional influence of the COVID-19 pandemic lockdowns on health behaviors and quality of life among chinese adults. International journal of environmental research and public health, 2020. 17(15): p. 5575.

Qi, M., et al., Physical activity, health-related quality of life, and stress among the Chinese adult population during the COVID19 pandemic. International Journal of Environmental Research and Public Health, 2020. 17(18): p. 6494.

Neria, Y., A. Nandi, and S. Galea, Post-traumatic stress disorder following disasters: a systematic review. Psychological medicine, 2008. 38(4): p. 467. 
Peteet, J.R., COVID-19 Anxiety. Journal of Religion and Health, 2020: p. 1.

Pierce, M., et al., Mental health before and during the COVID-19 pandemic: a longitudinal probability sample survey of the UK population. The Lancet Psychiatry, 2020. 7(10): p. 883-892.

Galea, S., R.M. Merchant, and N. Lurie, The mental health consequences of COVID-19 and physical distancing: The need for prevention and early intervention. JAMA internal medicine, 2020. 180(6): p. 817-818.

Liu, C., et al., Evidence for elevated psychiatric distress, poor sleep, and quality of life concerns during the COVID-19 pandemic among US young adults with suspected and reported psychiatric diagnoses. Psychiatry research, 2020. 292: p. 113345.

Lalonde, M., A new perspective on the health of Canadians: a working document. 1974: Ottawa.

Pomerleau, O., F. Bass, and V. Crown, Role of behavior modification in preventive medicine. New England Journal of Medicine, 1975. 292(24): p. 1277-1282.

WHO. Coronavirus disease 2019 (COVID-19): situation report, 72. 2020.

Henley, N. and R.J. Donovan, Threat appeals in social marketing: death as a 'special case'. International Journal of Nonprofit and Voluntary Sector Marketing, 1999. 4(4): p. 300-319.

Greenberg, J., S. Solomon, and T. Pyszczynski, Terror management theory of self-esteem and cultural worldviews: Empirical assessments and conceptual refinements, in Advances in experimental social psychology. 1997, Elsevier. p. 61-139.

Hikosaka, O., The habenula: from stress evasion to value-based decision-making. Nature reviews neuroscience, 2010. 11(7): p. 503-513.

Hsee, C.K., R. Hastie, and J. Chen, Hedonomics: Bridging decision research with happiness research. Perspectives on Psychological Science, 2008. 3(3): p. 224-243.

Solomon, S., J. Greenberg, and T. Pyszczynski, A terror management theory of social behavior: The psychological functions of self-esteem and cultural worldviews, in Advances in experimental social psychology. 1991, Elsevier. p. 93-159.

Jonas, E., et al., The Scrooge effect: Evidence that mortality salience increases prosocial attitudes and behavior. Personality and Social Psychology Bulletin, 2002. 28(10): p. 1342-1353.

Ben-Ari, O.T., V. Florian, and M. Mikulincer, Does a threat appeal moderate reckless driving? A terror management theory perspective. Accident Analysis \& Prevention, 2000. 32(1): p. 1-10.

Sowislo, J.F. and U. Orth, Does low self-esteem predict depression and anxiety? A meta-analysis of longitudinal studies. Psychological bulletin, 2013. 139(1): p. 213.

Manhas, C., Self-esteem and quality of life of people living with HIV/AIDS. Journal of Health Psychology, 2014. 19(11): p. 1471-1479.

WHO, Coronavirus disease (COVID-19) advice for the public: When and how to use masks. 2020.

State Council, C. Guidelines for the selection and use of different types of masks for preventing new coronavirus infection in different populations 2020 (in Chinese). 2020 [cited Feb 5, 2020 March 17, 2020].

Department of Health, H.K., Guidelines on prevention of coronavirus disease 2019 (COVID-19) for the general public. 2020.

Federal Ministry of Health, G., Daily updates on the coronavirus: Is wearing a surgical mask, as protection against acute respiratory infections, useful for members of the general public? 2020.

CDC. Coronavirus Disease 2019 (COVID-19): steps to prevent illness. 2020 March 17, 2020].

Feng, S., et al., Rational use of face masks in the COVID-19 pandemic. The Lancet Respiratory Medicine, 2020. 8(5): p. 434-436.

Nigro, F., et al., Changes in workflow to a University Pharmacy to facilitate compounding and distribution of antiseptics for use against COVID-19. Research in Social and Administrative Pharmacy, 2020.

Pappa, E., et al., Prescribed-drug utilization and polypharmacy in a general population in Greece: association with sociodemographic, health needs, health-services utilization, and lifestyle factors. European journal of clinical pharmacology, 2011. 67(2): p. 185-192.

Geitona, M., et al., Polypharmacy and adherence among diabetic patients in Greece. The Consultant Pharmacist@, 2018. 33(10): p. 562-571.

Onchonga, D., A Google Trends study on the interest in self-medication during the 2019 novel coronavirus (COVID-19) disease 


\section{(C) Center for Promoting Education and Research (CPER) USA}

wwW.cpernet.org

pandemic. Saudi Pharmaceutical Journal: SPJ, 2020. 28(7): p. 903.

Quispe-Cañari, J.F., et al., Prevalence of Self-Medication during the COVID-19 Pandemic in Peru. Available at SSRN 3688689, 2020.

Boyd, H.W. and S.J. Levy, New dimension in consumer analysis. Harvard Business Review, 1963. 41(6): p. 129-140.

Kasser, T., The Good Life or the Goods Life? Positive Psychology and Personal Well-Being in the Culture of Consumption. 2004.

Farquhar, M., Definitions of quality of life: a taxonomy. Journal of advanced nursing, 1995. 22(3): p. 502-508.

Gillingham, R. and W.S. Reece, A new approach to quality of life measurement. Urban Studies, 1979. 16(3): p. 329-332.

Engel, J.F., R. Blackwell, and P. Miniard, Customer behavior. Hinsdale, IL: Dryden, 1990.

Hooley, G.J. and J.A. Saunders, Competitive positioning: the key to marketing strategy. 1993: Prentice Hall.

Belk, R.W., Situational variables and consumer behavior. Journal of Consumer research, 1975. 2(3): p. 157-164.

Lai, A.W., Consumer values, product benefits and customer value: a consumption behavior approach. ACR North American Advances, 1995.

Moschis, G.P., Consumer socialization: A life-cycle perspective. 1987: Free Press.

Hoch, S.J. and G.F. Loewenstein, Time-inconsistent preferences and consumer self-control. Journal of consumer research, 1991. 17(4): p. 492-507.

Sengupta, J. and R. Zhou, Understanding impulsive eaters' choice behaviors: The motivational influences of regulatory focus. Journal of Marketing Research, 2007. 44(2): p. 297-308.

Chen, S., et al., Believing in Karma: The Effect of Mortality Salience on Excessive Consumption. Frontiers in psychology, 2019. 10: p. 1519.

Friese, M. and W. Hofmann, What would you have as a last supper? Thoughts about death influence evaluation and consumption of food products. Journal of Experimental Social Psychology, 2008. 44(5): p. 1388-1394.

Maxwell, S. and A. Kover, Negative affect: the dark side of retailing. Journal of Business Research, 2003. 56(7): p. 553-559.

Lachman, M.E. and S.L. Weaver, The sense of control as a moderator of social class differences in health and well-being. Journal of personality and social psychology, 1998. 74(3): p. 763.

Ruthig, J.C., et al., Comparative risk and perceived control: Implications for psychological and physical well-being among older adults. The Journal of social psychology, 2007. 147(4): p. 345-369.

Whalen, P.J., Fear, vigilance, and ambiguity: Initial neuroimaging studies of the human amygdala. Current directions in psychological science, 1998. 7(6): p. 177-188.

Kay, A.C., et al., Compensatory control: Achieving order through the mind, our institutions, and the heavens. Current Directions in Psychological Science, 2009. 18(5): p. 264-268.

Raghunathan, R. and M.T. Pham, All negative moods are not equal: Motivational influences of anxiety and sadness on decision making. Organizational behavior and human decision processes, 1999. 79(1): p. 56-77.

Li, M., et al., How does a public health emergency motivate People's impulsive consumption? an empirical study during the COVID-19 outbreak in China. International Journal of Environmental Research and Public Health, 2020. 17(14): p. 5019.

Baker, S.R., et al., How does household spending respond to an epidemic? consumption during the 2020 covid-19 pandemic. 2020, National Bureau of Economic Research.

Churchill, G.A. and D. Iacobucci, Marketing research: methodological foundations. 2006: Dryden Press New York.

Ilieva, J., S. Baron, and N.M. Healey, Online surveys in marketing research. International Journal of Market Research, 2002. 44(3): p. 1-14.

Group, W., Development of the World Health Organization WHOQOL-BREF quality of life assessment. Psychological medicine, 1998. 28(3): p. 551-558.

Michopoulos, I., et al., Hospital Anxiety and Depression Scale (HADS): validation in a Greek general hospital sample. Annals of general psychiatry, 2008. 7(1): p. 4.

WHO, Responding to community spread of COVID-19: interim guidance, 7 March 2020. 2020, World Health Organization.

Pappa, E., et al., Prescribed-drug utilization and polypharmacy in a general population in Greece: association with 
sociodemographic, health needs, health-services utilization, and lifestyle factors. European Journal of Clinical Pharmacology, 2011. 67(2): p. 185-192.

Yong, A.G. and S. Pearce, A beginner's guide to factor analysis: Focusing on exploratory factor analysis. Tutorials in quantitative methods for psychology, 2013. 9(2): p. 79-94.

Tavakol, M. and R. Dennick, Making sense of Cronbach's alpha. International journal of medical education, 2011. 2: p. 53-55.

Ercan, I., et al., Examining Cronbach alpha, theta, omega reliability coefficients according to sample size. Journal of modern applied statistical methods, 2007. 6(1): p. 27.

Kodinariya, T.M. and P.R. Makwana, Review on determining number of Cluster in K-Means Clustering. International Journal, 2013. 1(6): p. 90-95.

Johnson, R.A. and D.W. Wichern, Applied multivariate statistical analysis. Vol. 5. 2002: Prentice hall Upper Saddle River, NJ. Özabac1, N., Quality of life as a predictor of depression. Procedia-Social and Behavioral Sciences, 2010. 2(2): p. 2458-2463.

Hawryluck, L., et al., SARS control and psychological effects of quarantine, Toronto, Canada. Emerging infectious diseases, 2004. 10(7): p. 1206.

Lei, L., et al., Comparison of prevalence and associated factors of anxiety and depression among people affected by versus people unaffected by quarantine during the COVID-19 epidemic in southwestern China. Medical Science Monitor: International Medical Journal of Experimental and Clinical Research, 2020. 26: p. e924609-1.

Tang, F., et al., COVID-19 related depression and anxiety among quarantined respondents. Psychology \& Health, 2020: p. 1-15.

Werneck, A.O., et al., Lifestyle behaviors changes during the COVID-19 pandemic quarantine among 6,881 Brazilian adults with depression and 35,143 without depression. Ciência \& Saúde Coletiva, 2020. 25: p. 4151-4156.

Benke, C., et al., Lockdown, quarantine measures, and social distancing: Associations with depression, anxiety and distress at the beginning of the [1]COVID-19 pandemic among adults from Germany. Psychiatry Research, 2020. 293: p. 113462.

Johansson, R., et al., Depression, anxiety and their comorbidity in the Swedish general population: point prevalence and the effect on health-related quality of life. PeerJ, 2013. 1: p. e98.

Averina, M., et al., Social and lifestyle determinants of depression, anxiety, sleeping disorders and self-evaluated quality of life in Russia. Social Psychiatry and Psychiatric Epidemiology, 2005. 40(7): p. 511-518. 